\title{
A new species of Xestaspis (Araneae: Oonopidae) from the Pilbara region of Western Australia
}

\author{
Ricardo Ott ${ }^{1,2}$ and Mark S. Harvey ${ }^{2,3}$ \\ 'Museu de Ciências Naturais, Fundaçào Zoobotannica do Rio Grande do Sul, Rua Dr. Salvador França, \\ 1427, 90690-000, Porto Alegre, Rio Grande do Sul, Brazil. Email: rott@izb.rs.gosbr. \\ Department of Terrestrial Zoology, Western Australian Muse um, Locked Bag 49, Welshpool DC, \\ Westem Australia 6986, Australia. \\ School of Animal Biology, University of Western Australia, Crawley, \\ Westem Australia 6009, Australia. Email: mark.harvey@museum.wa.govau.
}

\begin{abstract}
A new species of the spider genus Xestaspis, X. limmai, is described from the arid Pilbara region of north-western Western Australia. It represents the first named species from Australia.
\end{abstract}

\section{INTRODUCTION}

Oonopid spiders are virtually cosmopolitan in distribution (Jocqué and Dippenaar-Schoeman 2006), with nearly 500 described species in 73 genera (Platnick 2008). They are small spiders, usually less than $4 \mathrm{~mm}$ in length and generally occur in habitats close to the ground, such as leaf litter and soil. The named Australian fauna is remarkably small but numerous undescribed species have been collected and await description.

The genus Xestaspis was proposed by Simon (1884) and currently includes ten species from different parts of the world: X. loricata ( $L$. Koch 1873) from Fiji; $X$. nitida Simon 1884, $X$. parumpunctata Simon 1893, X. recurva Strand 1906, $X$. sertata Simon 1907 and X. tumidula Simon, 1893 from Africa; X. sublaceis Simon 1893, from Sri Lanka; X. reimoseri Fage 1938 from Costa Rica; X. sis Saaristo and van Harten, 2006 and X. yemeni Saaristo and van Harten, 2006 from Yemen (Platnick 2008). The genus is, however, much more extensive with numerous undescribed species particularly from the Australasian region (Ott, unpublished data). As part of a large-scale review of the genus associated with a global review of the family Oonopidae (see http://research.amnh.org/ oonopidae/), we here describe a new species of Xestaspis from the arid-zone of Western Australia.

The specimens examined for this study are lodged in the Western Australian Museum, Perth (WAM). The descriptions follow the main protocol adopted by the PBI Oonopidae (http://researchamnhorg/ oonopidae). The specimens were examined with a Leica MZ16A microscope, and digital images were composed using the software program AutoMontage Pro Version 5.02 (p) utilizing multiple images taken with a Leica DFC 500 digital camera attached to the Leica microscope. Male pedipalps and female genitalia were cleared after immersion in clove oil for at least $24 \mathrm{~h}$ and examined with an Olympus BH-2 compound microscope and illustrated with the use of a drawing tube. The female ventral scuta and genitalia were submitted to additional examination after immersion in glycerol with $10 \%$ lactic acid at room temperature for at least one week.

The following abbreviations were used in the manuscript: ALE, anterior lateral eyes; PLE, posterior lateral eyes; PME, posterior median eyes.

\section{Family Oonopidae Simon 1890}

\section{Genus Xestaspis Simon 1884}

Xestaspis Simon 1884: 324.

\section{Type species}

Oonops loricalus L. Koch 1873 by original designation.

\section{Diagnosis}

Species of Xestaspis most closely resemble those of Gamasomorplan, from which they differ by the modified anterodorsal edge of the booklung covers, which bears a remarkable pointed tubercle. In addition, the body is heavily sclerotized, the carapace moderately high, with six welldeveloped eves, the endites lack any conspicuous modifications, with a complete set of abdominal scuta, and legs without obrious spines.

\section{Xestaspis linnaei sp. nov.}

$$
\text { Figures 1-4 }
$$

\section{Material examined}

\section{Holotype}

Australia: Western Australia: Z, Pilbara region: $23 \mathrm{~km}$ NE. of Warrawagine Homestead, survey 
site PHYE01, 1 July 2005-21 August 2006 (WAM T80495; PBI-OON 00004225).

\section{Paratypes}

Australia: Western Australia: Pilbara: 1 은 collected with holotype (WAM T83175; PBIOON 00005473); 1 $\delta, 27 \mathrm{~km} \mathrm{NE}$. of Warrawagine Homestead, survey site PHYE02, 1. July 2005-21 August 2006 (WAM T80494; PBI-OON 00004230).
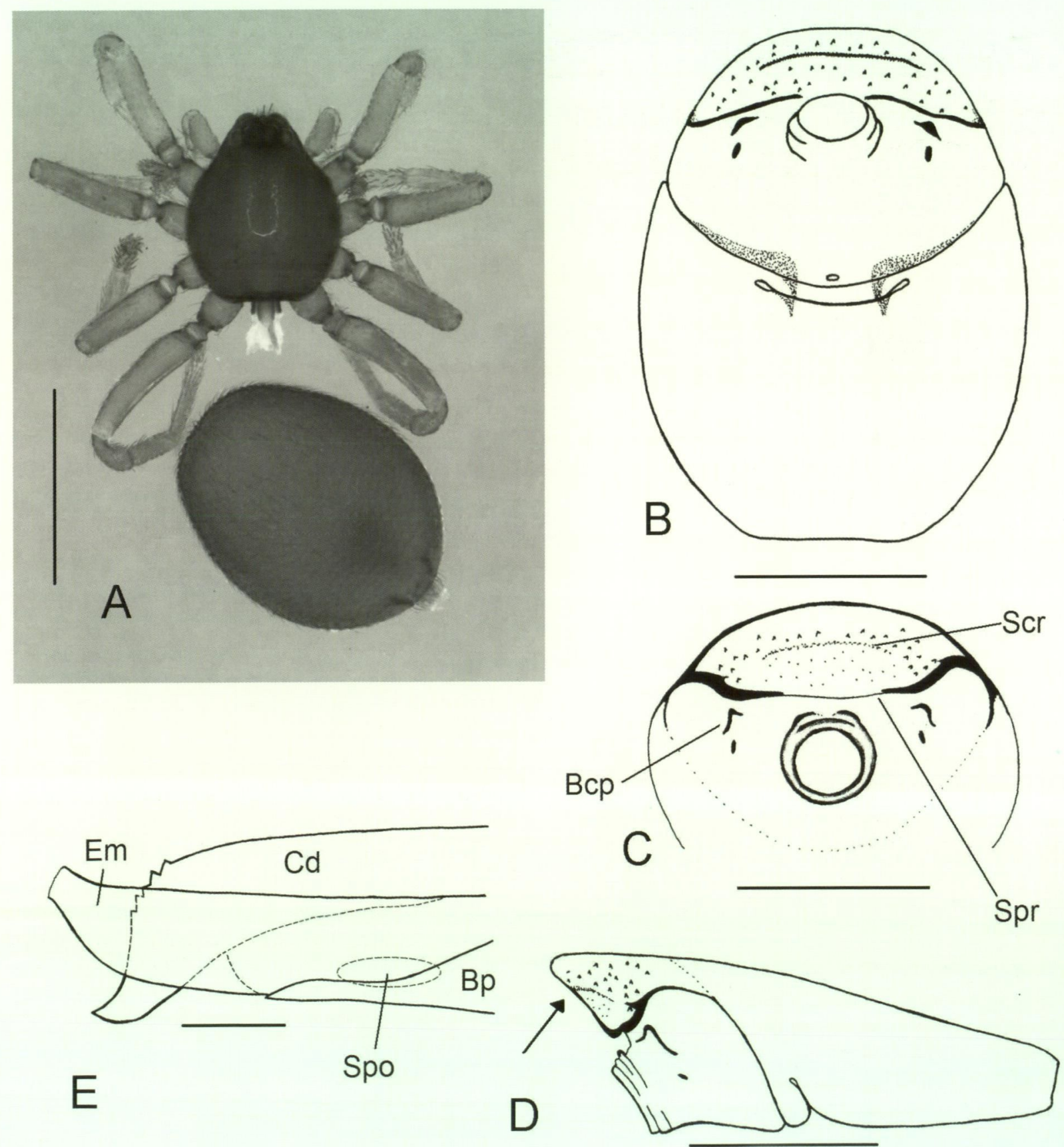

Figure 1 Xestaspis linnaei sp. nov., male: A, body, dorsal view. B-D, abdominal ventral scutum: B, ventral view; C, frontal view; D, lateral view. E, distal region of embolus, retrolateral view. Scale lines: A, $1.0 \mathrm{~mm}$; B-D, 0.5 $\mathrm{mm}$; E, $0.25 \mathrm{~mm}$; F, $0.025 \mathrm{~mm}$. Abbreviations: Bp, embolic set basal portion; Bcp, booklung covers, anterodorsal process; Cd, conductor; Em, embolus; Spo, spermatic opening; Spr, supra-pedicellar scutal ridge; Scr, semicircular ventral-arched ridge (arrows). 

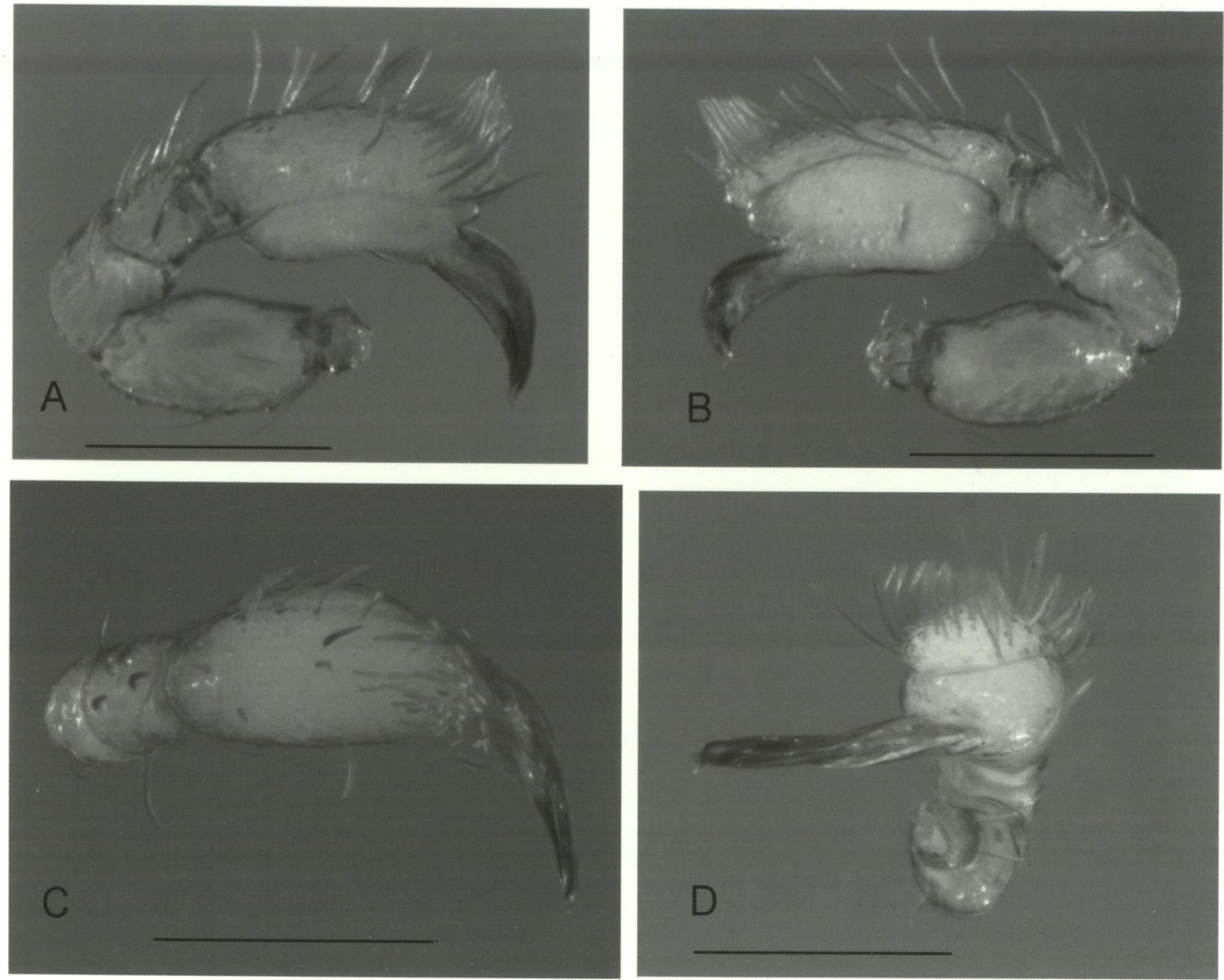

Figure 2 Xestaspis linnaei sp. nov., male, right palp: A, prolateral view; B, retrolateral view; C, dorsal view; D, frontal view. Scales: $0.25 \mathrm{~mm}$.

projecting far anteriad of the pedicel (almost twice the size of the pedicel diameter) with a conspicuous semicircular ventral-arched ridge between the supra-pedicellar scutal ridge and the dorsal end of the epigastric scutum (Figures 1B-D, 3B-D; arrows).

\section{Description}

\section{Male holotype}

Carapace: dark red-brown, pars thoracica granulate; clypeus high, ALE separated from edge of carapace by their radius or more. Eyes: PME circular; eye interdistances: ALE-ALE separated by ALE radius to ALE diameter, ALEPLE separated by less than ALE radius, PME-PME touching for less than half their length, PLE-PME separated by less than PME radius.

Sternum: orange-brown; posterior border quadrate and truncated.

Mouthparts: chelicerae, endites and labium orange-brown; chelicerae paturon inner margin slightly concave with a brush of short thorn-like setae.

Abdomen: rounded; booklung cover with anterodorsal process positioned as far from the pedicel as from the epigastric scutum lateral border (Figures 1B, 1C); abdominal setae serrate.

Abdominal scuta: orange-brown, surface with large setal bases; antero-superior border of the epigastric scutum, which extends far dorsal of the pedicel, almost twice the diameter of the pedicel (Figures 1C, 1D); scuto-pedicel region with straight scutal ridge forming a fold over anterior edge of booklungs (Figure 1D); conspicuous ventral-arched ridge between the main scutal ridge and anterodorsal end of epigastric scutum (Figure 1D); antero-dorsal post-epigastric scutum rounded (Figure 1B).

Legs: pale-orange.

Male genitalia: palpal bulb shorter than cymbium; lamellar embolus with straight and dorsally directed tip and sub-terminal and retrolateral 

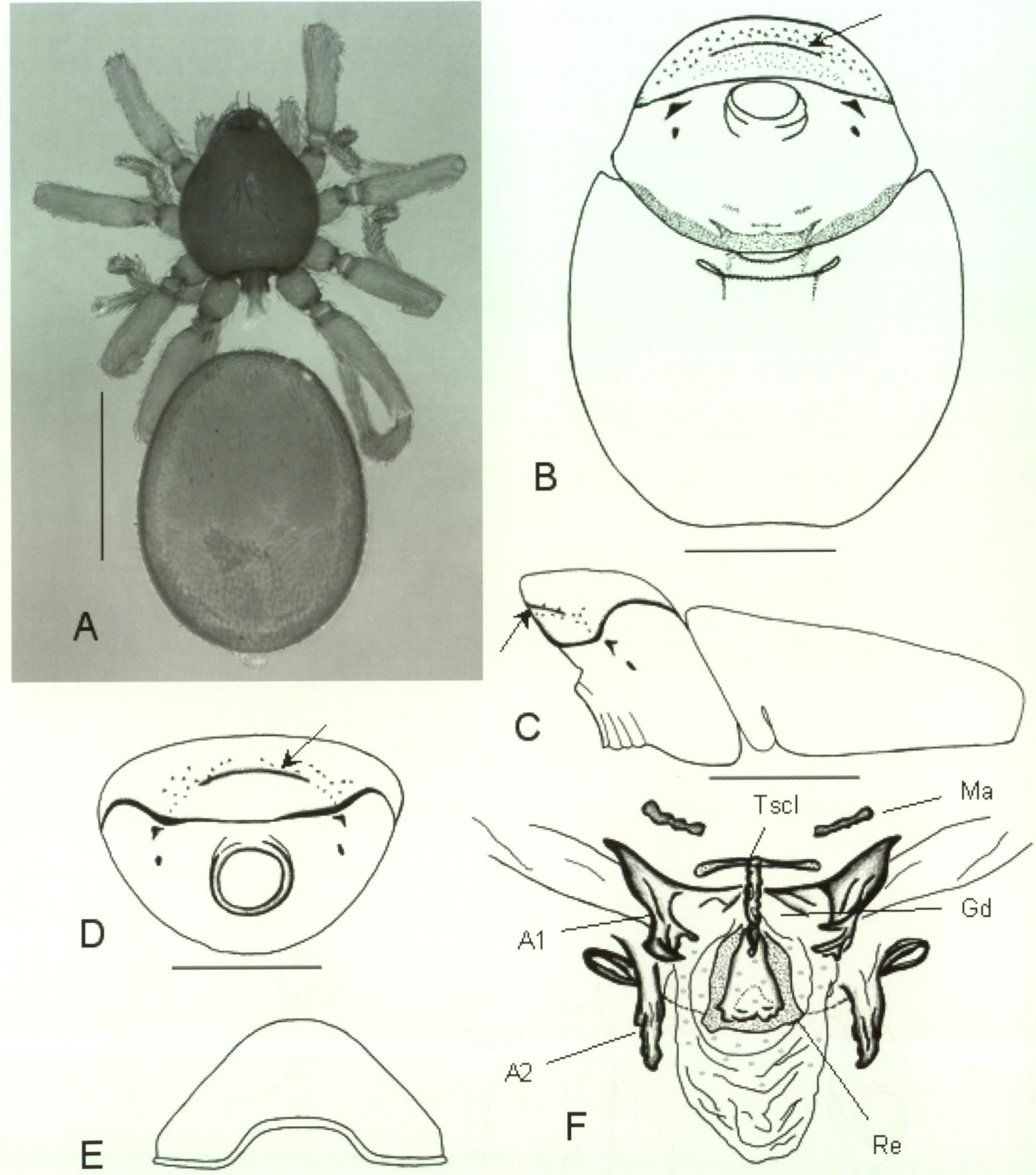

Figure 3 Xestaspis linnaei sp. nov., female paratype: A, body, dorsal view; B-D, abdominal ventral scutum; B, ventral view; C, lateral view; D, frontal view; E, carapace, posterior view; F, genitalia, dorsal view. Scale lines: A, $1.0 \mathrm{~mm}$; B-D, $0.5 \mathrm{~mm}$; E, F, $0.25 \mathrm{~mm}$. Abbreviations: A1, anterior apodeme; A2, posterior tracheal opening apodeme; Ma, epigastric scutum genital area muscle attachment sclerites; TScl, T-sclerite; Gd, glandular duct; Re, receptaculum; arrows, semicircular ventral-arched ridge. 


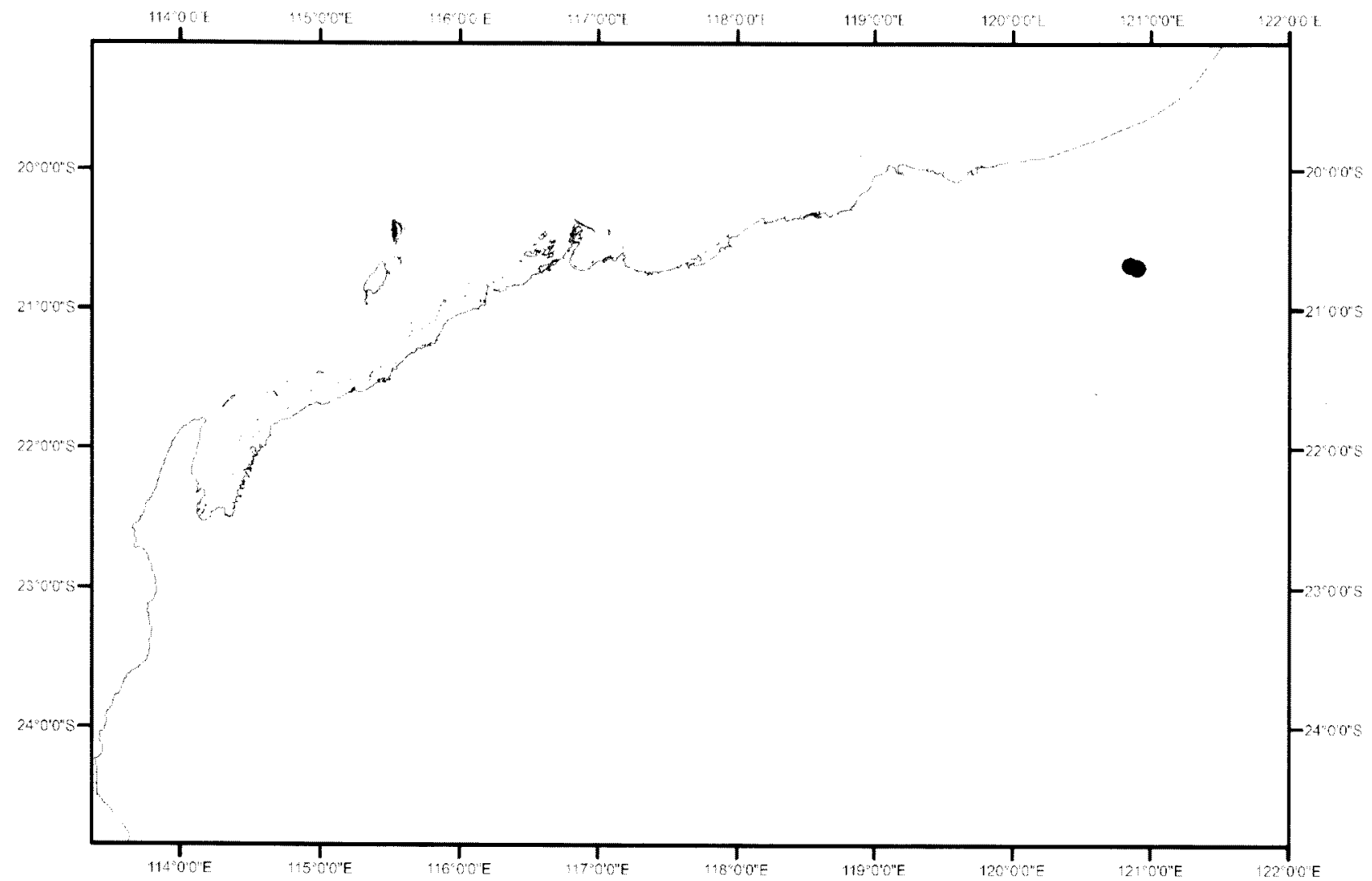

Figure 4 Distribution records of Xestaspis limacisp. nov

sperm duct opening; conductor shorter than embolus, with small denticles at anterodorsal end, and a retrolaterally curved ventral tip (Figures 1E, 2A-D).

Dimensions ( $\mathrm{mm}$ ): Total body length 2.23 . Carapace length 0.99 , width 0.82 , height 0.36 , carapace width (near posterior eye row) 0.38 . Eve group length 0.19 , width 0.34 . Clypeus height 0.06 . Chelicera length 0.36 . Sternum length 0.61 , width 0.48 . Dorsal scutum length 1.53 , width 1.16 . Post-epigastric scutum length (from epigastric furrow to posterior border of ventral scutum) 0.65 width 1.03. Leg I: femur 0.59 , patella 0.32 , tibia 0.38 , metatarsus 0.38 , tarsus 0.23 . Leg II: femur 0.57 , patella 0.32 , tibia 0.38 , metatarsus 0.38 , tarsus 0.23 . Leg III: femur 0.53, patella 0.29 , tibia 0.34 metatarsus 0.36 , tarsus 0.21. Leg IV: femur 0.73 patella 0.40 , tibia 0.53 , metatarsus 0.50 , tarsus 0.27 .

\section{Female paratype}

As for male, except as follows:

Mouthparts: Cheliceral paturon inner margin with inter-digitating setae not forming a conspicuous brush.

Abdominal scuta: scutal ridge fold over the booklungs less conspicuous than in male (Figure $3 \mathrm{C})$.
Female palp: Female tarsus slightly swollen distally with a dorsal patch of plumose setae.

Fenale genitalia: Receptaculum well delimited, bell-shaped, reaching to the posterior tracheal spiracle groove; short dorsal glandular duct attached to anterior portion of receptaculum and extending half way between epigastric furrow and posterior tracheal spiracle grove (Figure $3 F$ ). Large well delimited anterior T-shaped sclerite present. Anterior apodemes large, well sclerotized, slightly convergent posteriorly; posterior tracheal opening apodemes large, straight longitudinally, well sclerotized (Figure 3F).

Dimensions (mm): total body length 2.38 Carapace length 1.05 , width 0.88 , height 0.40 , carapace width (near posterior eve row) 0.40 . Eye group length 0.19 , width 0.34 . Clypeus 0.08 Chelicera length 0.38 . Sternum length 0.55 , width 0.44 . Dorsal scutum length 1.81, width 1.43. Postepigastric scutum length (from epigastric furrow to posterior border of ventral scutum) 0.86 , width 1.34. Leg I: femur 0.69, patella 0.36, tibia 0.46 , metatarsus 0.42, tarsus 0.23. Leg II: femur 0.67, patella 0.38 , tibia 0.48 , metatarsus $0.42,0.23$. Leg III: femur 0.63 , patella 0.34 , tibia 0.40 , metatarsus 0.40 , tarsus 0.22 . Leg IV: femur 0.82 , patella 0.46 , tibia 0.59 , metatarsus 0.55 , tarsus 0.32 . 


\section{Remarks}

Xestaspis linnaci is assigned to the genus Xestaspis due to the presence of a strong dorsoanterior process on the booklung covers (Figures $1 \mathrm{~B}-\mathrm{D}, 3 \mathrm{~B}-\mathrm{D})$. This species is only known from the Pilbara region of Western Australia (Figure 4) where the only known specimens were collected using pitfall traps.

\section{Etymology}

This species is named for Carolus Linnaeus (1707-1778), founder of the binomial system of taxonomic nomenclature.

\section{ACKNOWLEDGEMENTS}

The background work to this project was supported by a grant to $M$. Harvey by the Australian Biological Resources Study, and is currently supported by the Planetary Biodiversity Inventory project "The Megadiverse, Microdistributed Spider Family Oonopidae" funded by the National Science Foundation provided through grant DEB-0613754. We thank Dr Norman 1. Platnick for his support. The specimens were kindly provided by Brad Durrant and Nadine Guthrie, and were collected as part of the Pilbara Biological Survey conducted by the Department of Environment and Conservation. We also thank Julianne Waldock for her assistance and Dr Barbara Baehr and Dr Volker Framenau for their helpful comments on manuscript.

\section{REFERENCES}

Fage, L. (1938). Quelques arachnides provenant de fourmilieres ou de termitieres du Costa Rica. Bulletin du Muséum National d'Histoire Naturelle, Paris (2) 10: 369-376.

Jocqué, R. and Dippenaar-Schoeman, A. (2006). Spider families of the world. Musée Royal de l'Afrique Centrale: Tervuren.

Koch, L. (1873). Die Arachniden Australiens, vol. 1. Bauer und Raspe: Nürnberg.

Platnick, N.I. (2008). The world spider catalog, version 8.5. American Museum of Natural History, online at http://research.amnh.org/entomology/spiders/ catalog/index.html

Saaristo, M.I. and Harten, A. van (2006). The oonopid spiders (Arachnida: Araneae: Oonopidae) of mainland Yemen. Fauna of Arabia 21: 127-157.

Simon, E. (1884). Arachnides nouveaux d'Algérie. Bulletin de la Société Zoologique de France 9: 321-327.

Simon, E. (1890). Etudes arachnologiques. 22e Mémoire. XXXIV. Etude sur les arachnides de 1'Yemen. Annales de la Société Entomologique de France (6) 10: 77-124.

Simon, E. (1893). Études arachnologiques. 25e Mémoire. $X \mathrm{~L}$. Descriptions d'espèces et de genres nouveaux de l'ordre des Araneae. Annales de la Société Entomologique de France 62: 299-330.

Simon, E. (1907). Arachnides recueillis par L. Fea sur la côte occidentale d'Afrique. 1re partie. Annali del Museo Civico di Storia Naturale di Genova (3) 3: 218-323.

Strand, E. (1906). Diagnosen nordafrikanischer, hauptsächlich von Carlo Freiherr von Erlanger gesammelter Spinnen. Zoologischer Anzeiger 30: 604$637,655-690$.

Manuscript received 25 March 2008; accepted 14 July 2008. 